\title{
A new rebbachisaurid sauropod from the Aptian-Albian, Lower Cretaceous Rayoso Formation, Neuquén, Argentina
}

José I. Canudo, José L. Carballido, Alberto Garrido, and Leonardo Salgado

Acta Palaeontologica Polonica 63 (4), 2018: 679-691 doi:https://doi.org/10.4202/app.00524.2018

Rebbachisaurids are a group of basal diplodocimorph sauropods that diversified in Gondwana at the end of the Early Cretaceous and the beginning of the Late Cretaceous. It is a group of great palaeobiogeographical interest, for it clearly illustrates various processes of dispersal throughout Gondwana and to Laurasia prior to the breakup of Africa and South America. However, the relationships within the group are still under discussion owing to the scarcity of cranial material that would help clarify them. In the present paper we describe the new rebbachisaurid Lavocatisaurus agrioensis gen. et sp. nov. from the Aptian-Albian (Lower Cretaceous) of Neuquén (Argentina). Remains have been recovered belonging to an adult specimen (holotype) and two immature specimens (paratypes). Taken together, almost all the bones of the taxon are represented, including most of the cranium. Lavocatisaurus agrioensis gen. et sp. nov. is the first rebbachisaurid from Argentina with an almost complete cranium, making it possible to recognize differences with respect to other rebbachisaurids, such as the highly derived Nigersaurus . Among its most notable characters are the presences of a large preantorbital fenestra and maxillary teeth that are significantly larger than those of the dentary. Our phylogenetic study places Lavocatisaurus amongst basal rebbachisaurids, as the sister lineage to Khebbashia (the clade formed by Limaysaurinae + Rebbachisaurinae). This position, which is somewhat more derived than that previously suggested for Comahuesaurus and Zapalasaurus (the Argentinean rebbachisaurids closest in geographical and geological terms), reaffirms the presence of different basal rebbachisaurid lineages in the Early Cretaceous of Patagonia.

Key words: Dinosauria, Rebbachisauridae, phylogeny, Cretaceous, Rayoso Formation, Argentina.

José I. Canudo [jicanudo@unizar.es], Aragosaurus: Recursos geológicos y paleoambientes; IUCA, Facultad de Ciencias, Universidad de Zaragoza 50009, C/ Pedro Cerbuna 12, Zaragoza, Spain. José L. Carballido [jcarballido@mef.org.ar ], CONICET-Museo "Egidio Feruglio", Fontana 140, 9100 Trelew, Chubut, Argentina. Alberto C. Garrido [albertocarlosgarrido@gmail.com ], Museo Provincial de Ciencias Naturales "Prof. Dr. Juan 
Olsacher", Dirección Provincial de Minería, Etcheluz y

Ejército Argentino, 8340 Zapala, Neuquén, Argentina;

Departamento Geología y Petróleo, Facultad de Ingeniería,

Universidad Nacional del Comahue, Buenos Aires 1400,

8300 Neuquén, Neuquén, Argentina. Leonardo Salgado [1salgado@unrn.edu.arlsalgado@unrn.edu.ar], CONICET-Instituto de Investigación en Paleobiología y Geología, Universidad Nacional de Río Negro, Av. Gral. J.A. Roca 1242, 8332 General Roca, Río Negro, Argentina.

This is an open-access article distributed under the terms of the Creative Commons Attribution License (for details please see creativecommons.org), which permits unrestricted use, distribution, and reproduction in any medium, provided the original author and source are credited.

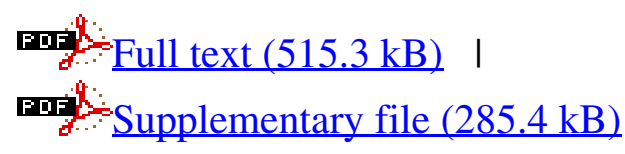

